ARTICLE

\title{
Three-component radical homo Mannich reaction
}

\author{
Shuai Shi ${ }^{1}$, Wenting Qiư ${ }^{1}$ Pannan Miao ${ }^{1}$, Ruining $\mathrm{Li}^{1}$, Xianfeng $\operatorname{Lin}^{1} \&$ Zhankui Sun $\mathbb{1}^{1 凶}$
}

\begin{abstract}
Aliphatic amine, especially tertiary aliphatic amine, is one of the most popular functionalities found in pharmaceutical agents. The Mannich reaction is a classical and widely used transformation for the synthesis of $\beta$-amino-carbonyl products. Due to an ionic nature of the mechanism, the Mannich reaction can only use non-enolizable aldehydes as substrates, which significantly limits the further applications of this powerful approach. Here we show, by employing a radical process, we are able to utilize enolizable aldehydes as substrates and develop the three-component radical homo Mannich reaction for the streamlined synthesis of $\gamma$-amino-carbonyl compounds. The electrophilic radicals are generated from thiols via the desulfurization process facilitated by visible-light, and then add to the electron-rich double bonds of the in-situ formed enamines to provide the products in a single step. The broad scope, mild conditions, high functional group tolerance, and modularity of this metal-free approach for the synthesis of complex tertiary amine scaffolds will likely be of great utility to chemists in both academia and industry.
\end{abstract}

\footnotetext{
${ }^{1}$ Shanghai Key Laboratory for Molecular Engineering of Chiral Drugs, School of Pharmacy, Shanghai Jiao Tong University, No. 800 Dongchuan Rd., 200240

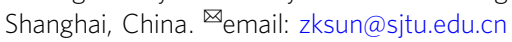


A mines are very important functional groups in medicinal chemistry and are present in many drugs ${ }^{1-3}$. They may be involved in H-bonding with target binding sites, either as hydrogen-bond acceptors or hydrogen-bond donors. In many cases, an amine could be protonated and a strong ionic interaction may take place with electron-negative part in the binding site ${ }^{4}$. Therefore, there is no doubt that aliphatic amine, especially tertiary aliphatic amine, is one of the most popular functional groups found in pharmaceutical agents ${ }^{2}$. Despite their importance, current synthetic techniques for amines are still limited $^{5-17}$. The development of mild, modular and efficient synthesis of amines is still in pressing need.

The Mannich reaction is a classical reaction for the synthesis of $\beta$ amino-carbonyl products ${ }^{18-23}$. It has been known for more than a century and is widely used in many areas of organic chemistry ${ }^{24-32}$. It has also been frequently proposed in many biosynthetic pathways, especially for alkaloids biosynthesis ${ }^{33,34}$. This reaction utilizes a nonenolizable aldehyde, a secondary amine and an enolizable carbonyl compound as starting materials, and affords useful $\beta$ amino-carbonyl products in one step. The use of non-enolizable aldehyde is essential to form the Schiff base intermediate, which acts as an electrophile and reacts with the enolizable carbonyl compound to provide the Mannich product. However, for the enolizable aldehyde, an electron-rich enamine intermediate will form, which will not react with the enolizable carbonyl compound (Fig. 1a). Therefore, the Mannich reaction is mainly for non-enolizable aldehydes. This obvious limitation poses great challenge for the further applications of this elegant and powerful transformation.

Seeking to overcome this obstacle, we hypothesized that the addition of an electrophilic radical I to the double bond of the electron-rich enamine would match the polarity request for radical reactions and generate radical intermediate II (Fig. 1b) ${ }^{35}$. This radical intermediate II could be stabilized by the adjacent nitrogen and then be intercepted through hydrogen atom transfer to provide $\gamma$-amino-carbonyl compound in a single step, while this type of products could not easily be accessed by other methods. To the best of our knowledge, this radical homo Mannich reaction has not been realized yet. There are several challenges. First of all, this radical-based reaction requires the use of mild conditions to selectively generate the electrophilic radical while not affecting other sensitive substances, such as the aldehyde, the enamine intermediate and the $\gamma$-amino-carbonyl product. These compounds could be reactive under radical conditions. Furthermore, the hydrogen atom transfer must be capable of rapidly intercepting radical intermediate II while not quenching the electrophilic radical I. Thirdly, other side reactions, such as the aldol reaction should be avoided under this condition. In spite of these challenges, herein we report the realization of our

a

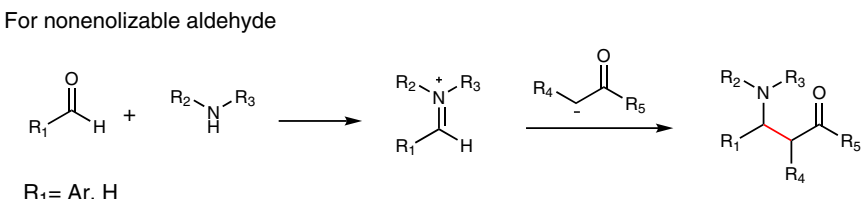

For enolizable aldehyde

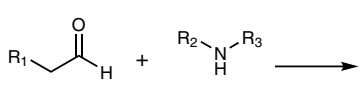<smiles>[R]N([B])C=C[2H]</smiles><smiles>[R3]CC([R5])=O</smiles>

b<smiles>[R]N[R5]N([R])CC</smiles><smiles>[R]C=CN([R])[B]</smiles>

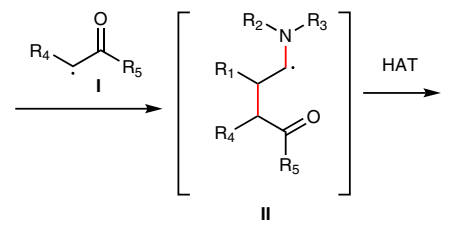<smiles>[R5]C(=O)C([R3])C([R])CN([R6])[R]</smiles>

c

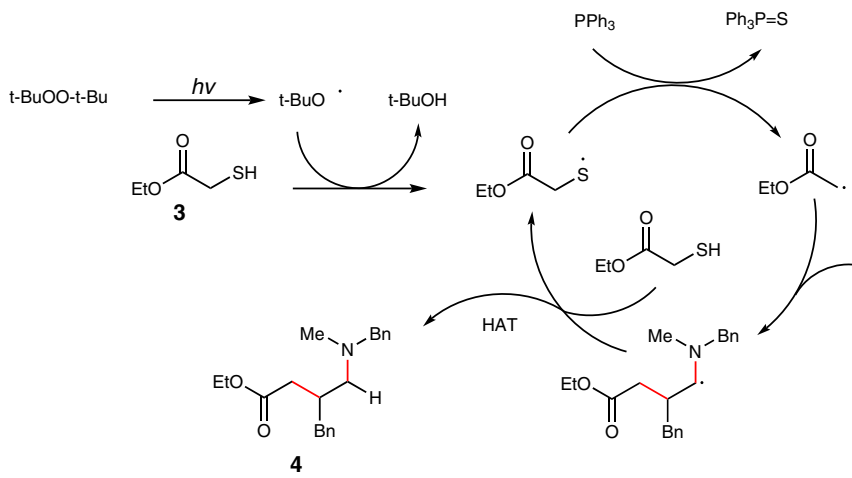<smiles>CN(/C=C/Cc1ccccc1)Cc1ccccc1</smiles><smiles>CC(C)C(C)O</smiles>

Fig. 1 Radical strategies for homo Mannich reaction. a The classical Mannich reaction. b Radical homo Mannich reaction. c Proposed mechanism for the three-component radical homo Mannich reaction. HAT hydrogen atom transfer. 


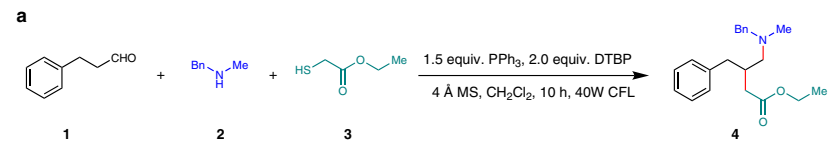

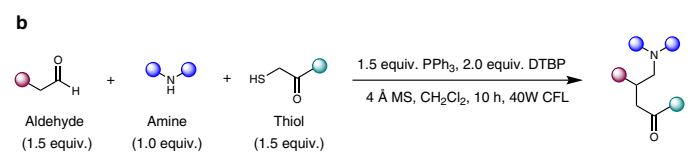

c<smiles>C[18O]COC(=O)CC(Cc1ccccc1)CN(C)[18OH]</smiles>

$91 \%$<smiles>CCOC(=O)CC(Cc1ccccc1)CN(C)CCCO</smiles>

10

$64 \%$<smiles>CCOC(=O)CC(Cc1ccccc1)CN(C)C</smiles>

16

$80 \%$<smiles>CCOC(=O)CC(Cc1ccccc1)CN1CCCCC1</smiles>

22

$90 \%$<smiles>CCOC(=O)CC(Cc1ccccc1)CN1CCC(O)CC1</smiles>

28

$95 \%$

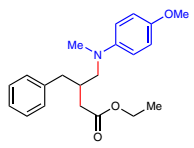

34

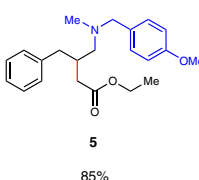

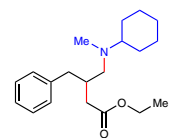

$95 \%$<smiles>CCOC(=O)CC(Cc1ccccc1)CN(Cc1ccc(OC)cc1)Cc1ccc(OC)cc1</smiles>

17

$60 \%$

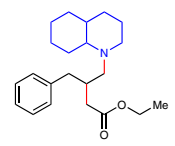

$23(\mathrm{dr} 2: 1)^{\mathrm{b}}$

$80 \%$

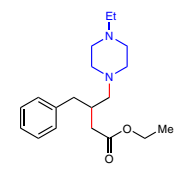

29

$77 \%$

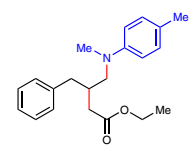

35<smiles>CCOC(=O)CC(Cc1ccccc1)CN(C)Cc1ccc(F)cc1</smiles>

6

$80 \%$

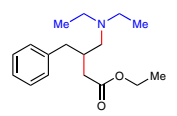

12<smiles>CCOC(=O)CC(Cc1ccccc1)CN1CCC1</smiles>

18

$81 \%$<smiles>CCOC(=O)CC(Cc1ccccc1)CN1CCC(C(=O)OCC)CC1</smiles>

24

$88 \%$

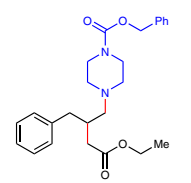

30

$85 \%$

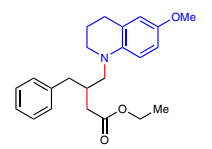

36
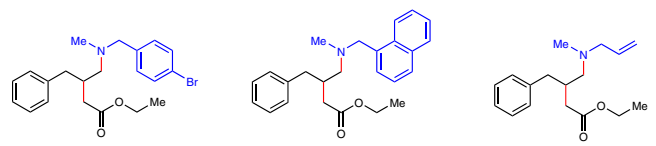

8

$70 \%$
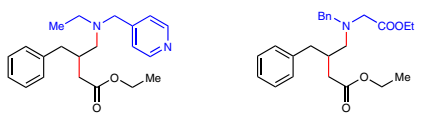

13<smiles>CCOC(=O)CC(Cc1ccccc1)CN1CCCC1</smiles><smiles>CCOC(=O)CC(Cc1ccccc1)CN1CCCC1CO</smiles>

20<smiles>CCOC(=O)CC(Cc1ccccc1)CN1CCC(N2CCCCC2)CC1</smiles>

25

$78 \%$<smiles>CCOC(=O)CC(Cc1ccccc1)CN1CCSCC1</smiles>

31

$75 \%$<smiles>CCOC(=O)CC(Cc1ccccc1)CN1CCC(Br)CC1</smiles>

26

$83 \%$<smiles>CCOC(=O)CC(Cc1ccccc1)CN1CCOCC1</smiles>

32

$89 \%$<smiles>CCOC(=O)CC(Cc1ccccc1)CN1CCCC1c1ccccc1</smiles>

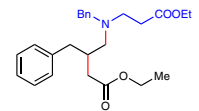

15

21

$83 \%(\text { dr } 7: 1)^{b}$<smiles>CCOC(=O)CC(Cc1ccccc1)CN1CCC(C)CC1</smiles>

27

$86 \%$<smiles>CCOC(=O)CC(Cc1ccccc1)CN1CCC(O)CC1</smiles>

33

$85 \%$

Fig. 2 Scope of the radical homo Mannich reaction. a The model reaction. b Optimal reaction conditions. DTBP Di-tert-butyl peroxide, MS molecular sieves. c Scope of the amine partner. ${ }^{a}$ triethyl phosphite (1.5 equiv.) was used instead of $\mathrm{PPh}_{3}$. bthe $\mathrm{dr}$ value was based on ${ }^{1} \mathrm{H}$ NMR.

hypothesis through the development of three-component radical homo Mannich reaction for the streamlined synthesis of complex tertiary amines. We chose to generate the electrophilic radical I through desulfurization of thiols ${ }^{36,37}$. We believe the mild conditions could tolerate different functionalities. Besides, the thiol itself is an excellent hydrogen atom transfer reagent to intercept radical intermediate $\mathbf{I I}^{38}$. The mild reaction conditions could also suppress other side reactions. Thus, based on our proposal, a possible mechanism is depicted in Fig. 1c. During the preparation of this paper, a multicomponent strategy for the construction of $\beta$-trifluoromethylated tertiary alkylamines was reported ${ }^{35}$.
Here we show, by employing a radical process, we are able to expand the scope of classical Mannich reaction to enolizable aldehydes for the streamlined synthesis of $\gamma$-amino-carbonyl compounds.

\section{Results}

Optimization studies. We started our model reaction (Fig. 2a) using 3-phenylpropanal (1), $\mathrm{N}$-methyl-1-phenylmethanamine (2), and ethyl 2-mercaptoacetate (3). Gratifyingly, this reaction worked perfectly well in DCM with $4 \AA$ Á molecular sieves and provided the desired product (4) in $91 \%$ isolated yield within 
<smiles>C=C(CCCN(C)C)OCC</smiles>

37

$90 \%$

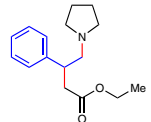

43

$84 \%$

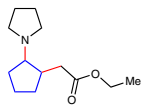

47

$68 \%(\operatorname{dr} 1.3: 1)^{\mathrm{a}}$

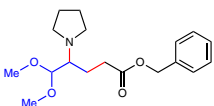

53

$69 \%$<smiles>C=C(CCC(c1ccccc1)N1CCCC1)OCC</smiles><smiles>CCCCCC(O)CCCC</smiles>

54

$65 \%$<smiles>CCOC(=O)CCC(c1cccnc1)N1CCCC1</smiles>

60

$72 \%$<smiles>CCC(C)C(CC)C(C)CC</smiles>

38

$91 \%$

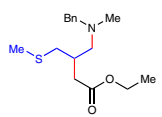

44

$90 \%$

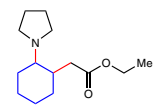

48

$71 \%(\mathrm{dr} 4: 1)^{\mathrm{a}}$
61
$58 \%$

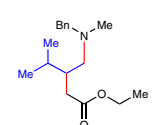

39

$89 \%$

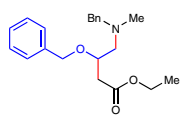

45

$76 \%$

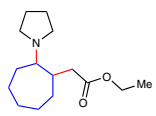

49

$74 \%(\text { dr } 6: 1)^{\mathrm{a}}$

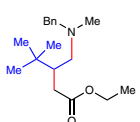

40

$85 \%$<smiles>CCOC(=O)CC(CCCCO)CCN(C)C</smiles>

46

$86 \%$

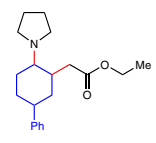

50

$72 \%(\operatorname{dr} 5: 1)^{\mathrm{a}}$

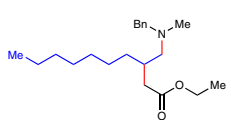

41

$83 \%$<smiles>CCOC(=O)CC(CN(C)C)C(C)CCC=CC(N)=O</smiles>

$42(\mathrm{dr} 2: 1)^{\mathrm{a}}$

$86 \%$

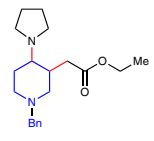

51

$70 \%(\operatorname{dr} 7: 1)^{\mathrm{a}}$

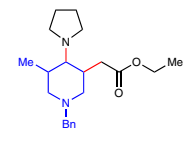

52

$29 \%$ b
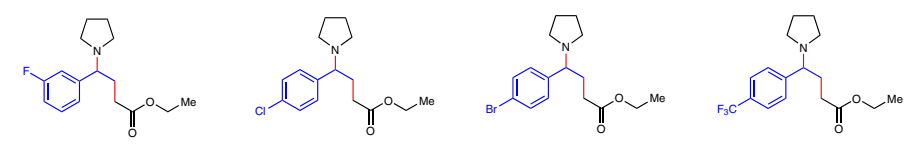

$\mathbf{5 6}$
$74 \%$

57
$67 \%$

$\mathbf{5 8}$
$67 \%$

59
$76 \%$<smiles>CCOC(=O)CCC(c1ccc2c(c1)-c1ccccc1C2)N1CCCC1</smiles>

62

$41 \%$<smiles>CN(C)[N+](=O)CC(CC(=O)OCc1ccccc1)Cc1ccccc1</smiles><smiles>CN(C)[C@@H](CC(=O)OCc1ccccc1)Cc1ccccc1</smiles><smiles>CCOC(=O)C1CCc2ccccc2C1C[N+](C)(C)O</smiles><smiles>C[NH+](C)CC1Cc2ccccc2CC1C(=O)OCc1ccccc1</smiles><smiles>CN(C)CC(Cc1ccccc1)C(CC(=O)O)C(=O)O</smiles>

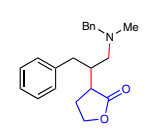

64

$76 \%(\text { dr } 1: 1)^{a}$

65

$64 \%(\mathrm{dr} 1: 1)^{\mathrm{a}}$

66

67

$78 \%\left(\right.$ dr 1:1) ${ }^{\mathrm{a}}$

$67 \%(\mathrm{dr} 1: 1)^{\mathrm{a}}$<smiles>CN(C)CC(CC(=O)N(C)C)Cc1ccccc1</smiles><smiles>CN(O)C(=O)CC(CCc1ccccc1)C12CC3CC(CC1C3)C2</smiles>

69

$88 \%$<smiles>CC(=O)C(C)C(Cc1ccccc1)C[NH+](C)C</smiles>

70

$70 \%(\text { dr } 1: 1)^{\mathrm{a}}$<smiles>CC(C)(C)C(c1ccccc1)c1ccccc1</smiles>

71

$78 \%(\mathrm{dr} 1: 1)^{\mathrm{a}}$<smiles>CN(C)[C@@H](CC(=O)OCCCOC(=O)CC(CCc1ccccc1)C[N+](C)(C)O)Cc1ccccc1</smiles>

72

$72 \%$

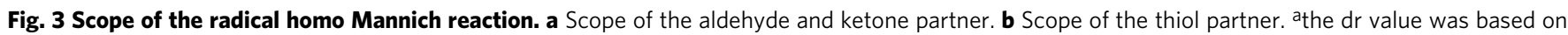
${ }^{1} \mathrm{H} N M R$.

$10 \mathrm{~h}$ under visible-light. Further experiments demonstrated that it could tolerate different solvents and different phosphoric reagents (for a detailed account of the optimization study, see Supplementary Table 1). The reaction could also be performed in greener solvent ${ }^{39}$, such as ethyl acetate. Control experiments revealed no reactions occurred in the absence of phosphoric reagent, DTBP (di-tert-butyl peroxide), or visiblelight. 
a<smiles>CC(C)COc1ccccc1CC(CCc1ccccc1)OC(C)C</smiles>

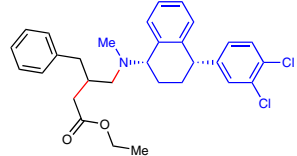

73

$85 \%$
74

$82 \%$

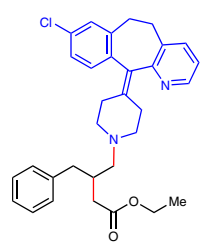

75

$80 \%$

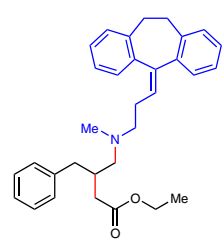

76

$85 \%$

b

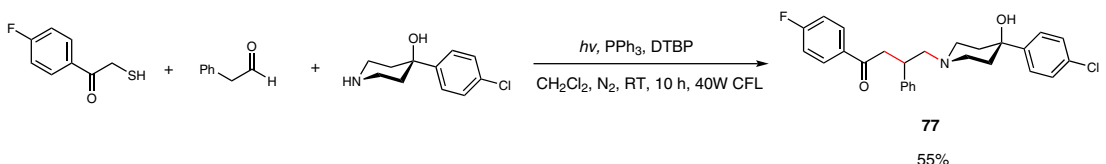

c

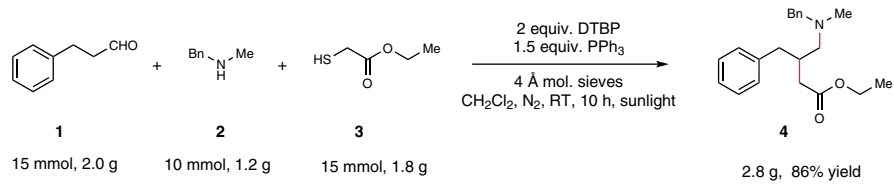

Fig. 4 Synthetic utilities of the radical homo Mannich reaction. a Late-stage modification of pharmaceutical agents. b Synthesis of the analog of Haloperidol. c Scale-up reaction for compound $\mathbf{4}$ under the sunlight.

a
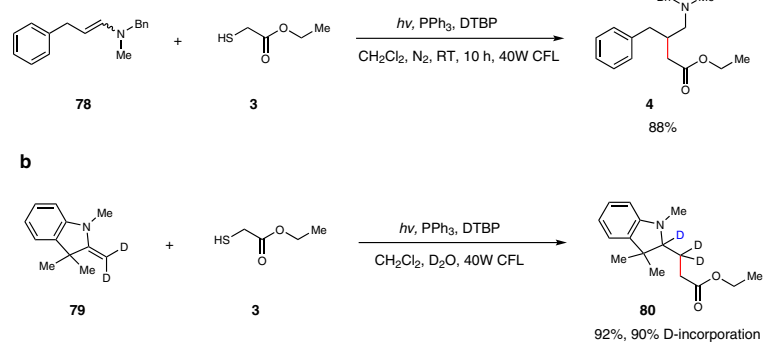

Fig. 5 Experimental observations for the proposed mechanism. a Direct addition to the enamine. $\mathbf{b}$ Deuterium-labeling study.

Evaluation of substrate scope. Having established the optimized conditions (Fig. 2b), we started to probe the scope of this transformation. We first evaluated this method with different amines (Fig. 2c). Both linear and cyclic amines worked well. A broad range of functional groups such as benzyl group $(4,14-16)$, paramethoxy benzyl group (5 and 17), aryl fluoride (6), aryl bromide (7), pyridine (13), azetidine (18), pyrrolidine (19-21), piperidine (22-28, 33), tertiary amine (25), ether (28), piperazine (29), benzyloxycarbonyl (30), thiomorpholine (31), and morpholine (32), could be well tolerated and provided the products in good to excellent yields. More sensitive functionalities which could be reactive under normal Mannich reaction conditions, such as ester $(14,15$ and 24), cyanide (10 and 27), bromide (26), and even free hydroxy group (33), proved to be compatible and furnished the products in good to excellent yields, reflecting the mildness of the reaction conditions. As for substrate 9 with a terminal alkene, the radical added to the enamine rather than the alkene, probably due to the electron-rich nature of the enamine intermediate. Less reactive anilines could also be successfully transformed into the corresponding products in good yields (34 and 35) when triethyl phosphite was used instead of $\mathrm{PPh}_{3}$. However, with sterically more hindered aniline substrate (36), the yield was unsatisfactory.

The scope of the aldehyde partner was then examined (Fig. 3a). Various aldehydes proceeded efficiently to give the products in good to excellent yields. Notable examples included the ones bearing alkene (42), sulfide (44), ether (45), benzyl (45), and even chloride group (46).

Ketones also proved to be suitable substrates. Different sized cyclic ketones worked efficiently (47-49). Benzyl protected piperidin-4-one also reacted well (51). For unsymmetric ketones, the reaction took place at the less hindered sites (52-53).

Aryl methyl ketone with different substituents, either electrondonating groups (55) or electron-withdrawing groups (56-59), proceeded to afford the desired products. Pyridine substrate also provided the product in good yield (60).

We next surveyed the scope of thiols (Fig. 3b). Different esters (63-66), lactones (67) and amides (68) bearing a-sulfide were efficiently converted to the corresponding products in good to excellent yields. It is worthy pointing out that disulfides could be compatible partners as well (63). a-Substituted sulfide ketones were also readily accommodated (70-71). When there are two reacting sites, we were able to isolate the bi-functionalized product in $72 \%$ yield $(\mathbf{7 2})$.

Synthetic utilities. In a final effort to establish the generality of this protocol, we did a late-stage modification of highly functionalized commercial drugs. As dialkylamine motifs are present in a range of small-molecule drugs and pre-clinical candidates, we selected four pharmaceutical agents and subjected them to the radical homo Mannich reactions (Fig. 4a). Each of these structurally complex amines underwent smooth transformations and furnished the tertiary amine products in very good yields (73-76). We also applied our method for the direct synthesis of pharmaceutical drugs. The analog of Haloperidol (77) could be synthesized in $55 \%$ yield in one step (Fig. $4 \mathrm{~b}$ ). At last, we performed the 
model reaction on $10 \mathrm{mmol}$ scale under the sunlight. Compound 4 was isolated in high yield $(2.8 \mathrm{~g}, 86 \%)$, which indicated a promising scale-up potential of this method using green energy (Fig. 4c).

Mechanistic studies. A number of experimental observations provide support for the proposed mechanism (Fig. 5). First, we synthesized the enamine (78) and subjected it to the reaction conditions. The desired product (4) was obtained in $88 \%$ yield, suggesting that the in-situ formed enamine was the reaction intermediate for the three-component reaction. Then we performed the radical addition of ethyl 2-mercaptoacetate (3) to enamine (79) in $\mathrm{D}_{2} \mathrm{O} / \mathrm{DCM}$. We were able to isolate the deuterated product $(\mathbf{8 0})$ in $92 \%$ yield with $90 \%$ deuteration, which clearly demonstrated that radical intermediate II was formed and then intercepted though deuterium atom transfer during the reaction (for a detailed account of the mechanism study, see Supplementary Fig. 5 and Fig. 6).

\section{Discussion}

Compared with the classical Mannich reaction, which utilizes non-enolizable aldehyde and provides $\beta$-amino-carbonyl product via an ionic pathway, this three-component radical homo Mannich reaction makes use of enolizable aldehyde and affords $\gamma$ amino-carbonyl scaffold though a radical process. We anticipate that this method will be complementary to the classical Mannich reaction and it will simplify the design and construction of complex tertiary alkyl amine for chemists in both academia and industry.

\section{Methods}

General procedure for three-component radical homo Mannich reaction. To a 10 -mL oven-dried round bottomed flask were added $4 \AA$ molecular sieves $(1 \mathrm{~g})$ and triphenylphosphine $(393 \mathrm{mg}, 1.5 \mathrm{mmol})$. The flask was degassed three times and protected with $\mathrm{N}_{2}$ before anhydrous DCM $(6 \mathrm{ml})$ was added. Amine $(1 \mathrm{mmol})$, aldehyde/ketone $(1.5 \mathrm{mmol})$, thiol $(1.5 \mathrm{mmol})$, and DTBP $(292 \mathrm{mg}, 2 \mathrm{mmol}$, $0.37 \mathrm{ml}$ ) were added into the reaction mixture in order by micro-syringe. The reaction was stirred and irradiated using two $40 \mathrm{~W}$ household CFL bulbs $(6 \mathrm{~cm}$ away, to keep the reaction at room temperature) at room temperature for $10 \mathrm{~h}$. When the reaction was complete, EtOAc was added $(20 \mathrm{ml})$. The mixture was dried with sodium sulfate, filtered and concentrated. The residue was purified by column chromatography on silica to give the product.

\section{Data availability}

Materials and methods, experimental procedures, useful information, mechanistic studies, optimization studies, ${ }^{1} \mathrm{H}$ NMR spectra, ${ }^{13} \mathrm{C}$ NMR spectra, and mass spectrometry data are available in the Supplementary Information. Raw data are available from the corresponding author on reasonable request.

Received: 1 November 2020; Accepted: 12 January 2021; Published online: 12 February 2021

\section{References}

1. Lovering, F., Bikker, J. \& Humblet, C. Escape from flatland: Increasing saturation as an approach to improving clinical success. J. Med. Chem. 52, 6752-6756 (2009).

2. Roughley, S. D. \& Jordan, A. M. The medicinal chemist's toolbox: An analysis of reactions used in the pursuit of drug candidates. J. Med. Chem. 54, 3451-3479 (2011).

3. Blakemore, D. C. et al. Organic synthesis provides opportunities to transform drug discovery. Nat. Chem. 10, 383-394 (2018).

4. Dill, KenA. Dominant forces in protein folding. Biochemistry 29, 7133-7155 (1990).

5. Yang, Y., Shi, S. L., Niu, D., Liu, P. \& Buchwald, S. L. Catalytic asymmetric hydroamination of unactivated internal olefins to aliphatic amines. Science 349, 62-66 (2015).

6. Musacchio, A. J. et al. Catalytic intermolecular hydroaminations of unactivated olefins with secondary alkyl amines. Science 355, 727-730 (2017).
7. Johnston, C. P., Smith, R. T., Allmendinger, S. \& MacMillan, D. W. C Metallophotoredox-catalysed $s p^{3}-s p^{3}$ cross-coupling of carboxylic acids with alkyl halides. Nature 536, 322-325 (2016).

8. Matier, C. D., Schwaben, J., Peters, J. C. \& Fu, G. C. Copper-catalyzed alkylation of aliphatic amines induced by visible light. J. Am. Chem. Soc. 139, 17707-17710 (2017).

9. Huang, L., Arndt, M., Gooßen, K., Heydt, H. \& Gooßen, L. J. Late transition metal-catalyzed hydroamination and hydroamidation. Chem. Rev. 115, 2596-2697 (2015).

10. Trowbridge, A., Reich, D. \& Gaunt, M. J. Multicomponent synthesis of tertiary alkylamines by photocatalytic olefin-hydroaminoalkylation. Nature 561, 522-527 (2018)

11. Kumar, R., Floden, N. J., Whitehurst, W. G. \& Gaunt, M. J. A general carbonyl alkylative amination for tertiary amine synthesis. Nature 581, 415-420 (2020).

12. Abdel-Magid, A. F. \& Mehrman, S. J. A review on the use of sodium triacetoxyborohydride in the reductive amination of ketones and aldehydes. Org. Process Res. Dev. 10, 971-1031 (2006).

13. Robak, M. T., Herbage, M. A. \& Ellman, J. A. Synthesis and applications of tert-butanesulfinamide. Chem. Rev. 110, 3600-3740 (2010).

14. Pirnot, M. T., Wang, Y. M. \& Buchwald, S. L. Copper hydride catalyzed hydroamination of alkenes and alkynes. Angew. Chem. Int. Ed. 55, 48-57 (2016).

15. Grogan, G. Synthesis of chiral amines using redox biocatalysis. Curr. Opin. Chem. Biol. 43, 15-22 (2018).

16. Ruiz-Castillo, P. \& Buchwald, S. L. Application of palladium-catalyzed C-N cross-coupling reactions. Chem. Rev. 116, 12564-12649 (2016).

17. Kalck, P. \& Urrutigoïty, M. Tandem hydroaminomethylation reaction to synthesize amines from alkenes. Chem. Rev. 118, 3833-3861 (2018).

18. Mannich, C. \& Krösche, W. Ueber ein kondensationsprodukt aus formaldehyd, ammoniak und antipyrin. Arch. Pharm. 250, 647-667 (1912).

19. Mannich, C. Synthesis of $\beta$-ketonic bases. J. Chem. Soc. Abstr. 112, 634 (1917)

20. Mannich, C. Synthesis of $\beta$-ketonic bases. Arch. Pharm. 255, 261-276 (1917).

21. Arend, M., Westermann, B. \& Risch, N. Modern variants of the Mannich reaction. Angew. Chem. Int. Ed. 37, 1044-1070 (1998)

22. Cordova, A. The direct catalytic asymmetric mannich reaction. Acc. Chem. Res. 37, 102-112 (2004).

23. Meyer, C. C., Ortiz, E. \& Krische, M. J. Catalytic reductive aldol and mannich reactions of enone, acrylate, and vinyl heteroaromatic pronucleophiles. Chem. Rev. 120, 3721-3748 (2020).

24. Kobayashi, S. \& Ishitani, H. Catalytic enantioselective addition to imines. Chem. Rev. 99, 1069-1094 (1999).

25. Weiner, B., Szymanski, W., Janssen, D. B., Minnaard, A. J. \& Feringa, B. L. Recent advances in the catalytic asymmetric synthesis of beta-amino acids. Chem. Soc. Rev. 39, 1656-1691 (2010).

26. Candeias, N. R., Montalbano, F., Cal, P. M. S. D. \& Gois, P. M. P. Boronic acids and esters in the petasis-borono mannich multicomponent reaction. Chem. Rev. 110, 6169-6193 (2010).

27. Casiraghi, G., Battistini, L., Curti, C., Rassu, G. \& Zanardi, F. The vinylogous aldol and related addition reactions: ten years of progress. Chem. Rev. 111, 3076-3154 (2011).

28. Phipps, R. J., Hamilton, G. L. \& Toste, F. D. The progression of chiral anions from concepts to applications in asymmetric catalysis. Nat. Chem. 4, 603-614 (2012).

29. de Graaff, C., Ruijter, E. \& Orru, R. V. A. Recent developments in asymmetric multicomponent reactions. Chem. Soc. Rev. 41, 3969-4009 (2012).

30. Dalpozzo, R., Bartoli, G. \& Bencivenni, G. Recent advances in organocatalytic methods for the synthesis of disubstituted 2- and 3-indolinones. Chem. Soc. Rev. 41, 7247-7290 (2012).

31. Shirakawa, S. \& Maruoka, K. Recent developments in asymmetric phasetransfer reactions. Angew. Chem. Int. Ed. 52, 4312-4348 (2013).

32. Mao, B., Fañanás-Mastral, M. \& Feringa., B. L. Catalytic asymmetric synthesis of butenolides and butyrolactones. Chem. Rev. 117, 10502-10566 (2017)

33. Wenkert, E. Biosynthesis of indole alkaloids. The aspidosperma and iboga bases. J. Am. Chem. Soc. 84, 98-102 (1962).

34. Leete, E. Alkaloid biosynthesis. Annu. Rev. Plant Physiol. 18, 179-196 (1967).

35. Kolahdouzan, K., Kumar, R. \& Gaunt, M. J. Visible-light mediated carbonyl trifluoromethylative amination as a practical method for the synthesis of $\beta$ trifluoromethyl tertiary alkylamines. Chem. Sci. 11, 12089-12094 (2020).

36. Qin, Q., Wang, W., Zhang, C., Song, S. \& Jiao, N. A metal-free desulfurizing radical reductive $\mathrm{C}-\mathrm{C}$ coupling of thiols and alkenes. Chem. Commun. 55, 10583-10586 (2019)

37. Shi, S., Li, R., Rao, L. \& Sun, Z. A mild, general, and metal-free method for site specific deuteration induced by visible light using $\mathrm{D}_{2} \mathrm{O}$ as the source of deuterium atoms. Green Chem. 22, 669-672 (2020).

38. Glass, R. S. Sulfur radicals and their application. Top. Curr. Chem. 376, 22 (2018).

39. Capello, C., Fischer, U. \& Hungerbühler, K. What is a green solvent? A comprehensive framework for the environmental assessment of solvents. Green Chem. 9, 927-934 (2007). 


\section{Acknowledgements}

We thank Shanghai Jiao Tong University for financial support.

\section{Author contributions}

Z.S. conceived the project. S.S., W.Q, P.M., R.L. and X.L. performed all experiments. All the authors analyzed the results. Z.S. and S.S. wrote the manuscript.

\section{Competing interests}

The authors declare no competing interests.

\section{Additional information}

Supplementary information The online version contains supplementary material available at https://doi.org/10.1038/s41467-021-21303-3.

Correspondence and requests for materials should be addressed to Z.S.

Peer review information Nature Communications thanks Carlos Vila Descals and Jae Kyung Jung for their contribution to the peer review of this work. Peer reviewer reports are available.
Reprints and permission information is available at http://www.nature.com/reprints

Publisher's note Springer Nature remains neutral with regard to jurisdictional claims in published maps and institutional affiliations.

(c) Open Access This article is licensed under a Creative Commons Attribution 4.0 International License, which permits use, sharing, adaptation, distribution and reproduction in any medium or format, as long as you give appropriate credit to the original author(s) and the source, provide a link to the Creative Commons license, and indicate if changes were made. The images or other third party material in this article are included in the article's Creative Commons license, unless indicated otherwise in a credit line to the material. If material is not included in the article's Creative Commons license and your intended use is not permitted by statutory regulation or exceeds the permitted use, you will need to obtain permission directly from the copyright holder. To view a copy of this license, visit http://creativecommons.org/ licenses/by/4.0/.

(c) The Author(s) 2021 